\title{
Computational study on effects of rib height and thickness on heat transfer enhancement in a rib roughened square channel
}

\author{
ANUJ K SHUKLA and ANUPAM DEWAN* \\ Department of Applied Mechanics, Indian Institute of Technology Delhi, Hauz Khas, New Delhi 110016, India \\ e-mail: adewan@am.iitd.ac.in
}

MS received 8 January 2015; revised 24 September 2015; accepted 31 January 2016

\begin{abstract}
A computational study was carried out for the heat transfer augmentation in a three-dimensional square channel fitted with different types of ribs. The standard $k-\varepsilon$ model and its two variants (RNG and realizable) were used for turbulence modeling. The predictions were compared with available experimental and computational results. Three rib configurations were used in the present study: $90^{\circ}$ continuous attached ribs, $60^{\circ}$ $\mathrm{V}$-shaped broken attached thick and thin ribs. It was observed that the maximum heat transfer occurs at the normalized rib spacing $(p / e)=10$ in the case of $90^{\circ}$ attached ribs. The effects of the blockage ratio and rib thickness were investigated for $60^{\circ} \mathrm{V}$-shaped broken ribs with $R e=10,000-30,000$ and p/e $=10$. It was observed that the average Nusselt number decreases with an increase in the Reynolds number for almost all configurations studied in the present study. For the $60^{\circ} \mathrm{V}$-shaped broken ribs, increasing the blockage ratio had an adverse effect on the heat transfer. It was also observed that thin ribs perform better than thick ribs.
\end{abstract}

Keywords. Heat transfer enhancement; turbulent flow; ribbed channel; broken ribs; CFD.

\section{Introduction}

Ribs and rough surfaces are widely used to enhance the heat transfer in any closed channel flow with heat transfer applications. These promote turbulence resulting in the convective heat transfer enhancement. The heat transfer enhancement methods are grouped in two types, namely, the active method and the passive method. Heat transfer enhancement through ribs falls in the category of the passive method. Many other passive heat transfer enhancement methods, such as rough surfaces, baffles, or any turbulent promoter surfaces can be used. These roughness elements disturb the viscous sub-layer of the flow. However, an increase in the heat transfer is accompanied at the cost of the pressure drop. Two types of ribbed surfaces are used to enhance the heat transfer, i.e., attached and detached ribs. Ribs as a turbulent promoters have been used for many years to enhance the heat transfer in many applications, such as heat exchangers, internal cooling of a gas turbine blades, turbo machines and nuclear reactors, etc. Internal cooling passages are made in some of the turbine blades during its manufacturing and hence to allow high inlet temperatures to achieve high thrust/weight ratios and low specific fuel consumption.

The ribs are adiabatic and therefore these do not work as extended heat transfer surfaces but produce a disturbance in the flow. The presence of ribs in a closed channel produces

*For correspondence a complex flow field due to flow separation and reattachment between the ribs, which increases turbulence level and this leads to an increased heat transfer coefficient. The effect of a turbulent flow caused by a roughness element is different in fluids and gases due to a difference in their thermal resistances. Figure 1 shows formation of separation bubble and reattachment produced by ribs.

Figure 2 shows different rib configurations considered in the present study, where $e, s$ and $d$ denote the rib height, rib thickness and hydraulic diameter (refer figure 3) respectively. $90^{\circ}$ continuous ribs had thickness of $3 \mathrm{~mm}$. For $60^{\circ}$ $\mathrm{V}$-shaped broken ribs the thick ribs were of dimensions $s / d=e / d$ and thin ribs considered were of dimension $s / d=0.0125$. Two vertical walls of the test section were made up of steel having $0.05 \mathrm{~mm}$ thickness [1]. These two walls were heated and ribs were placed over these walls. Other two horizontal walls and ribs were made of perspex sheet [1].

Many techniques have been used by different researchers to improve the heat transfer in a duct flow. Webb et al [2] studied heat transfer and friction in tubes with repeated rib roughness. They concluded that the heat transfer and friction correlations may be extended to a wider range of blockage ratios by the virtue of the law of the wall similarity. Han et al [3] showed that ribs at a $45^{\circ}$ angle of attack increased heat transfer performance at a given friction power compared to ribs at a $90^{\circ}$ angle of attack. Han et al [4] showed that a V-shaped rib produces the highest heat transfer enhancement, while an A-shaped rib generates the 
greatest pressure drop. Han and Zhang [5] found that a $60^{\circ}$ parallel broken rib or a $60^{\circ} \mathrm{V}$-shaped broken rib provides a higher heat transfer augmentation than a $45^{\circ}$ parallel broken rib or a $45^{\circ} \mathrm{V}$-shaped broken rib and it is higher than that produced by $90^{\circ}$ broken ribs as well. Braun et al [6] experimentally and numerically studied turbulent heat transfer in a channel with periodically arranged rib roughness elements. They adopted LES for the numerical investigation and observed that LES can capture the flow structures correctly. Bonhoff et al [7] presented numerical and experimental investigations of developed flow and heat transfer in coolant channels with $45^{\circ}$ ribs. Gao and Sunden [8] studied the heat transfer and pressure drop in a ribroughened rectangular duct. They observed that the V-ribs pointed downstream produced a high heat transfer enhancement. Chandra et al [9] studied surface heat transfer and friction characteristics of a fully developed turbulent air flow in a square channel with varying number

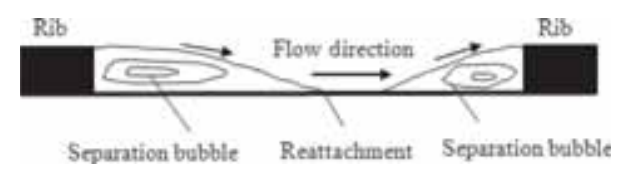

Figure 1. Formation of separation bubble and reattachment.

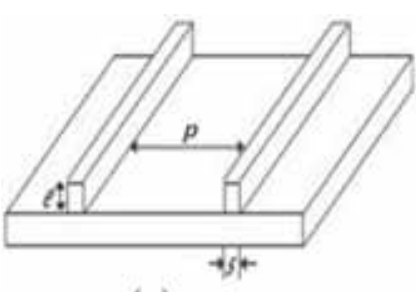

(a)

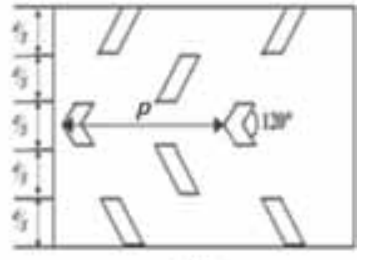

(b)
Figure 2. Different attached rib configurations for (a) $90^{\circ}$ continuous rib and (b) $60^{\circ} \mathrm{V}$-shaped broken ribs.

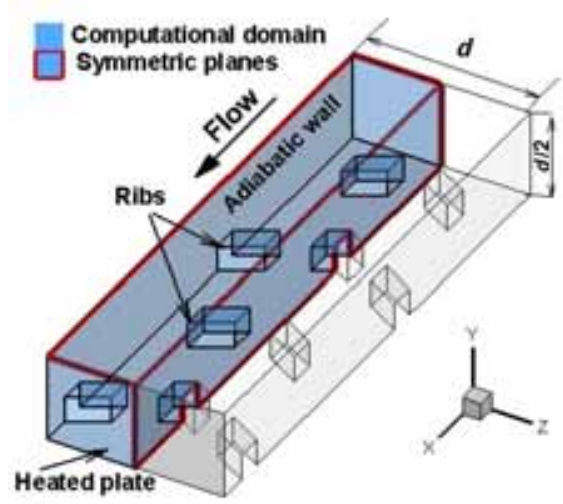

(a) of ribbed walls. They concluded that the heat transfer coefficient and friction factor increased with an increase in the number of ribbed walls.

Kim and Kim [10] presented a numerical procedure to optimize the shape of two-dimensional channel with periodic ribs mounted on both walls to enhance the turbulent heat transfer. Tanda [11] presented an experimental study on heat transfer in rectangular channels with transverse and $\mathrm{V}$-shaped broken ribs using liquid crystal thermography technique. Gao and Sunden [12] investigated the flow characteristics in rectangular channel with $60^{\circ}$ parallel, crossed and V-shaped ribs using PIV measurements. They showed strong effects of the inclined ribs on the flow characteristics by the development of secondary flows. Onbasioglu and Onbasioglu [13] concluded that an enhancement of heat transfer depends upon several geometric parameters and especially on the angle of inclination. Sewall et al [14] concluded that large eddy simulation (LES) produces the correct physics both quantitatively and qualitatively within $10-15 \%$ of experimental values. Vijiapurapu and Cui [15] investigated turbulent flow through pipes fitted with uniformly spaced ribs using LES. They considered two categories of ribs i.e. intermediate type roughness (closely spaced ribs) and the one based on pitch ratio. They observed that the reattachment occurred next to the downstream ribs in the intermediate type of roughness and for the second category of rib (based on pitch ratio) the flow separated downstream of the rib and reattachment occurred between the ribs and on the pipe wall. They observed that LES computation is suitable for such flow problems. Further Gupta et al [16] measured the local heat transfer distribution in a doubled wall rib square and observed that the variation of the normalized rib pitch $(p / e)$ by keeping the blockage ratio $(e / d)$ constant has a negligible effect on the average heat transfer augmentation for broken ribs. Eiamsa-ard and Promvonge [17] observed that due to the recirculation flow caused by grooves, enhancement of heat transfer occurs in a channel.

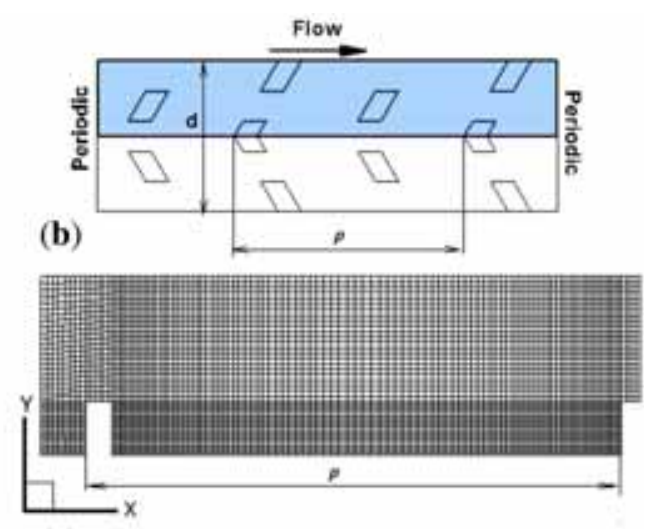

(c)

Figure 3. Computational domain (a) isometric three-dimensional view; (b) top view; and (c) grid selection. 
Sriharsha et al [1] showed experimentally that an increase in rib height in case of broken ribs results in a decreased heat transfer and detachment of broken ribs did not help in the heat transfer augmentation. Tanda [18] investigated the effect of rib spacing of $45^{\circ}$ angle ribs on one or two walls on heat transfer in a rectangular channel. They observed that the maximum heat transfer occurs at $p / e=13.66$ for single ribbed wall channel and at $p / e=6.66-10$ for the two ribbed wall channel. Peng et al [19] investigated the convection heat transfer with different types of ribs in a rectangular channel through experimental measurements and numerical analysis. They observed that the $\mathrm{V}$-shaped rib-bed plate provides better thermal and hydraulic performances than the $90^{\circ}$ rib-bed plate because it not only disrupts the boundary layer but also produces secondary longitudinal vortices, which cause an enhancement of heat transfer. Promvonge et al [20] showed that if the rectangular test duct is sufficiently large, the rib duct flow can be considered as fully developed periodic flow. Smulsky et al [21] studied heat transfer in turbulent separated flow behind a rib on the surface of a square channel at different orientation angles relative to the flow direction. They showed that with a decrease in the angle of rib orientation, the coordinates of reattachment area, pressure and heat transfer maxima move towards the ribs and a reduction in recirculation zone makes heat transfer enhancement possible. Tang and Zhu [22] investigated distribution of vorticity, turbulent kinetic energy and local heat transfer. They observed a low value of the local heat transfer just behind the rib due to flow separation and concluded that a rise in the Nusselt number is due to the development of longitudinal vortices provoked by inclined broken ribs.

It is clear from the above-mentioned literature review that most studies have been performed using thick and continuous ribs. It can also be observed that most studies are reported with experimental investigations and a small number of computational studies on broken ribs have been reported in the literature. The effect of blockage ratio $(e / d)$ and rib thickness $(s / d)$ on the heat transfer augmentation has found less attention of researchers. It is clear from the literature that the blockage ratio $(e / d)$, rib thickness $(s / d)$ and rib spacing $(p / e)$ affect the flow field and heat transfer characteristics in a duct flow with heat transfer application. Vijiapurapu and Cui [23] studied the fully developed turbulent flows in rib roughened circular pipes using LES and RANS models. They observed that the time-averaged flow measurements were well captured by both RANS models and LES, however RANS models failed to capture the instantaneous information. They suggested that the RANS models can be used in order to get time-averaged flow information only. Therefore, in order to obtain an insight into flow features, i.e., instantaneous and time averaged fields one should use LES but at a cost of large computational requirements. Often we want to study limited quantitative properties of a turbulent flow, such as the average heat transfer taking place from a surface and average forces on a surface. For such situations, we can use RANS models rather than LES (large eddy simulation) and DNS (direct numerical simulation) in order to save high computational efforts involved with LES and DNS.

In the present study, we have computationally investigated the effect of $90^{\circ}$ continuous ribs and $60^{\circ}$ $\mathrm{V}$-shaped broken ribs to gain a fundamental insight of the flow field and heat transfer. With the aim of enhancement of heat transfer the effects of blockage ratio $(e / d)$ and rib thickness $(s / d)$ were investigated for $60^{\circ} \mathrm{V}$-shaped broken ribs with Reynolds number ranging from 10,000-30,000.

\section{Computational procedure and mathematical modeling}

A numerical simulation was carried out in the present study to investigate the heat transfer augmentation in a threedimensional square channel fitted with different types of ribs. The governing Reynolds-averaged equations for the conservation of mass, momentum and energy can be written as Eqs. (1) to (3).

Continuity equation

$$
\frac{\partial\left(\rho \overline{U_{i}}\right)}{\partial x_{i}}=0
$$

\section{Momentum equation}

$$
\frac{\partial}{\partial x_{j}}\left(\rho \bar{U}_{i} \bar{U}_{j}\right)=-\frac{\partial \bar{P}}{\partial x_{i}}+\frac{\partial}{\partial x_{j}}\left[\mu\left(\frac{\partial \bar{U}_{i}}{\partial x_{j}}+\frac{\partial \bar{U}_{j}}{\partial x_{i}}\right)-\rho \overline{u_{i}^{\prime} u_{j}^{\prime}}\right] .
$$

The term $-\rho \overline{u_{i}^{\prime} u_{j}^{\prime}}$ in the momentum equation (2) is called the Reynolds stress and its presence in this equation leads to a closure problem.

Energy equation

$$
\rho c_{p} \overline{U_{i}} \frac{\partial \bar{T}}{\partial x_{i}}=k_{a} \frac{\partial^{2} \bar{T}}{\partial x_{i}^{2}}-\frac{\partial}{\partial x_{i}}\left(\rho c_{p} \overline{u_{i}^{\prime} T^{\prime}}\right),
$$

where $\rho$ denotes the density of the fluid and $\bar{U}_{i}$ the mean component of velocity in $x_{i}$ direction and $u^{\prime}$ denotes the fluctuating component of velocity and $k_{a}$ the thermal conductivity of the fluid. The other symbols used here have their usual meanings.

Turbulence models to close the system of momentum and energy equations are described in the following section.

\subsection{Turbulence models}

In the present study the standard $k-\varepsilon$ model and its two variants (RNG and realizable models) were used to close the system of governing equations. These models are based on the Boussinesq approximation (Eq. 4), which relates the Reynolds stresses to the mean velocity gradients as 


$$
-\rho \overline{u_{i}^{\prime} u_{j}^{\prime}}=\mu_{t}\left(\frac{\partial \bar{U}_{i}}{\partial x_{j}}+\frac{\partial \bar{U}_{j}}{\partial x_{i}}\right)-\frac{2}{3} \rho \delta_{i j} k
$$

where $k$ denotes the turbulent kinetic energy and is defined as $k=\frac{1}{2} \overline{u_{i}^{\prime} u_{i}^{\prime}}$, and $\delta_{i j}$ denotes the Kronecker delta and $\mu_{t}$ the turbulent or eddy viscosity.

Turbulent transport of heat and other scalar quantities are modeled in the same way as that for momentum equation (5).

$$
-\rho \overline{u_{i}^{\prime} \Phi^{\prime}}=\Gamma_{t}\left(\frac{\partial \bar{\Phi}}{\partial x_{j}}\right) .
$$

The turbulent Prandtl number $\left(P r_{t}\right)$ is defined as the ratio of the turbulent viscosity $\left(\mu_{t}\right)$ and turbulent thermal diffusivity $\left(\Gamma_{t}\right)$ and is given as

$$
\operatorname{Pr}_{t}=\frac{\mu_{t}}{\Gamma_{t}}
$$

A typical value of the turbulent Prandtl number used in engineering computation is approximately 1 [24].

2.1a Standard $k-\varepsilon$ model: The standard $k-\varepsilon$ model [25] is one of the most widely used models and is frequently used in various applications. It is a two equation semi-empirical model with one transport equation for turbulent kinetic energy $(k)$ and other for dissipation of turbulent kinetic energy $(\varepsilon)$.

The eddy viscosity is modeled as

$$
\mu_{t}=\rho c_{\mu} \frac{k^{2}}{\varepsilon}
$$

where $C_{\mu}$ denotes an empirical model constant.

Transport equations for turbulent kinetic energy $(k)$ and dissipation ( $\varepsilon$ ) may be written as

$$
\begin{gathered}
\frac{\partial}{\partial \mathrm{x}_{\mathrm{i}}}\left(\rho k \bar{U}_{i}\right)=\frac{\partial}{\partial \mathrm{x}_{\mathrm{j}}}\left[\left(\mu+\frac{\mu_{t}}{\sigma_{k}}\right) \frac{\partial k}{\partial \mathrm{x}_{\mathrm{j}}}\right]+G_{k}-\rho \varepsilon \\
\frac{\partial}{\partial \mathrm{x}_{\mathrm{i}}}\left(\rho \varepsilon \bar{U}_{i}\right)=\frac{\partial}{\partial \mathrm{x}_{\mathrm{j}}}\left[\left(\mu+\frac{\mu_{t}}{\sigma_{\varepsilon}}\right) \frac{\partial \varepsilon}{\partial \mathrm{x}_{\mathrm{j}}}\right]+C_{1 \varepsilon} \frac{\varepsilon}{k}\left(G_{k}\right)-C_{2 \varepsilon} \rho \frac{\varepsilon^{2}}{k} .
\end{gathered}
$$

In these equations $G_{k}$ represents the generation of turbulent kinetic energy due to the mean velocity gradients. The values of the model constants used in these equations are $C_{\mu}=0.09, C_{1 \varepsilon}=1.44, C_{2 \varepsilon}=1.92, \sigma_{k}=1.0, \sigma_{\varepsilon}=1.31$ [26]. Here $\sigma_{\varepsilon}$ and $\sigma_{k}$ denote the turbulent Prandtl numbers for $\varepsilon$ and $k$, respectively.

2.1b $R N G k-\varepsilon$ model: The RNG $k-\varepsilon$ model was derived using the renormalization group theory. The RNG $k-\varepsilon$ model is similar in form to the standard $k-\varepsilon$ model. It has an additional term in its dissipation rate equation that significantly improves the accuracy of rapidly strained flows and swirling flows [24].
Transport equations for turbulent kinetic energy $(k)$ and dissipation $(\varepsilon)$ may be written as

$$
\frac{\partial}{\partial x_{i}}\left(\rho k \bar{U}_{i}\right)=\mu_{t} S^{2}+\frac{\partial}{\partial x_{i}}\left(\alpha_{k} \mu_{\text {eff }} \frac{\partial k}{\partial x_{i}}\right)-\rho \varepsilon
$$

where $S \equiv \sqrt{2 S_{i j} S_{i j}}, \quad S_{i j} \equiv \frac{1}{2}\left(\frac{\partial \bar{U}_{j}}{\partial x_{i}}+\frac{\partial \bar{U}_{i}}{\partial x_{j}}\right)$

$$
\begin{aligned}
\frac{\partial}{\partial x_{i}}\left(\rho \varepsilon \bar{U}_{i}\right)= & C_{1 \varepsilon}\left(\frac{\varepsilon}{k}\right) \mu_{t} S^{2}+\frac{\partial}{\partial x_{i}}\left(\alpha_{\varepsilon} \mu_{\text {eff }} \frac{\partial \varepsilon}{\partial x_{i}}\right)-C_{2 \varepsilon} \rho\left(\frac{\varepsilon^{2}}{k}\right) \\
& -R_{\varepsilon},
\end{aligned}
$$

where $\mu_{\text {eff }}$ denotes the effective viscosity and $R_{\varepsilon}$ is written as

$$
\begin{gathered}
\mu_{e f f}=\mu+\mu_{t}=\mu+\rho C_{\mu} \frac{k^{2}}{\varepsilon} \text { and } \\
R_{\varepsilon}=\frac{C_{\mu} \rho \eta^{3}\left(1-\eta / \eta_{0}\right)}{1+\beta \eta^{3}} \frac{\varepsilon}{k},
\end{gathered}
$$

where $\eta=\frac{S \varepsilon}{k}, \eta_{0}=4.38, \beta=0.012$. The model constants $\alpha_{k}, \alpha_{\varepsilon}, C_{1 \varepsilon}, C_{2 \varepsilon}$ are derived using the RNG theory.

2.1c Realizable $k-\varepsilon$ model: The realizable $k-\varepsilon$ model differs from the standard $k-\varepsilon$ model in two ways [24]: (a) it contains a new formulation for the turbulent viscosity and (b) a new transport equation for the dissipation rate is derived from an exact equation for the transport of the mean square vorticity fluctuations. The transport equations for turbulent kinetic energy $(k)$ and dissipation $(\varepsilon)$ may be written as

$$
\frac{\partial}{\partial \mathrm{x}_{\mathrm{i}}}\left(\rho k \bar{U}_{i}\right)=\frac{\partial}{\partial \mathrm{x}_{\mathrm{j}}}\left[\left(\mu+\frac{\mu_{t}}{\sigma_{k}}\right) \frac{\partial k}{\partial \mathrm{x}_{\mathrm{j}}}\right]+G_{k}-\rho \varepsilon
$$

$\frac{\partial}{\partial \mathrm{x}_{\mathrm{i}}}\left(\rho \varepsilon \bar{U}_{i}\right)=\frac{\partial}{\partial \mathrm{x}_{\mathrm{j}}}\left[\left(\mu+\frac{\mu_{t}}{\sigma_{\varepsilon}}\right) \frac{\partial \varepsilon}{\partial \mathrm{x}_{\mathrm{j}}}\right]+\rho C_{1} S_{\varepsilon}-\rho C_{2} \frac{\varepsilon^{2}}{k+\sqrt{v \varepsilon}}$,

where $C_{1}=\max \left[0.43 \frac{\eta}{\eta+S}\right], \eta=\frac{S k}{\varepsilon}$ and $S_{\varepsilon}$ is the user defined source term.

$$
S i j=\frac{\bar{U}_{i, j}+\bar{U}_{j, i}}{2}
$$

Eddy viscosity

$$
\mu_{t}=\rho c_{\mu} \frac{k^{2}}{\varepsilon},
$$

where

$$
C_{\mu}=\frac{1}{A_{0}+A_{S} \frac{k U^{*}}{\varepsilon}},
$$

where

$$
U^{*}=\sqrt{S_{i j} S_{i j}+\bar{\Omega}_{i j} \bar{\Omega}_{i j}}
$$


$\bar{\Omega}_{i j}=$ denotes the rate of rotation tensor and $A_{0}$ and $A_{s}$ denote the model constants.

All the governing equations were solved numerically using the finite volume method and the second order upwind scheme was used as the discretization scheme. The SIMPLE (Semi-Implicit Method for Pressure Linked Equations) algorithm was used for the pressure-velocity coupling. The computations were performed using ANSYS FLUENT 14. We assumed the solutions to be converged for the normalized residual values less than $10^{-5}$ for all the variables except $10^{-9}$ for the energy equation.

Three parameters considered in the present study, namely, the Reynolds number $(R e)$, local Nusselt number $\left(N u_{x}\right)$ and area average Nusselt number $\left(N u_{a v}\right)$ are defined as

$$
R e=\frac{\rho U d}{\mu} \text {. }
$$

The local heat transfer is measured by the local Nusselt number $(\mathrm{Nu})$ (a quantitative measure of the convective heat transfer taking place at the surface) and is given by

$$
N u=\frac{h d}{k_{a}},
$$

where $h$ is the local heat transfer coefficients and is given by

$$
h=\frac{q_{w}}{T_{b}-T_{w}},
$$

where $T_{b}$ and $T_{w}$ are the temperatures of the bulk fluid and wall, respectively.

The area average Nusselt number is given by

$$
N u_{a v}=\frac{1}{A} \int N u_{x} d A .
$$

The Dittus-Boelter equation for turbulent flow is an explicit function for calculating the Nusselt number $\left(N u_{0}\right)$ for the smooth duct. For $R e \geq 10,000$ for smooth duct turbulent flow with constant heat flux condition this correlation is given as

$$
N u_{0}=0.0243 \operatorname{Re}^{0.8} \operatorname{Pr}^{0.4} .
$$

Two additional parameters, namely, friction factor and thermal enhancement performance factor $(T E P F)$, have been widely considered by many authors to study the thermal performance of a rib roughened channel $[1,18,20]$.

We have computed the Fanning friction factor $f$ by the average pressure drop, $\Delta P$, across the periodic duct length, $p$, and is given by

$$
f=\frac{(\Delta P / p) d}{2 \rho U^{2}} .
$$

The relative significance of pumping power was accessed by normalizing the friction factor $(f)$ obtained from equation (17) with the friction factor $\left(f_{0}\right)$ associated with the fully developed turbulent flow in smooth pipe given by Blasius correlation $(3,000<\operatorname{Re}<100,000)$ as

$$
f_{0}=0.046 \mathrm{Re}^{-0.2} \text {. }
$$

Thermal performance enhancement factor (TPEF) is obtained by the ratio of the heat transfer coefficient $(h)$ of an enhanced surface to that of the smooth surface $\left(h_{0}\right)$ at an equal pumping power and is given as

$$
T P E F=\left.\frac{h}{h_{0}}\right|_{p p}=\left.\frac{N u}{N u_{0}}\right|_{p p}=\left(N u / N u_{0}\right) /\left(f / f_{0}\right)^{1 / 3},
$$

where $N u_{0}$ and $f_{0}$ denotes the Nusselt number and friction factor for the smooth surface duct, respectively.

\section{Description of flow field}

In this present study we considered a horizontal square duct of cross section $0.04 \mathrm{~m} \times 0.04 \mathrm{~m}$ fitted with $90^{\circ}$ continuous and $60^{\circ} \mathrm{V}$-shaped broken ribs. Ribs were placed repeatedly on two opposite vertical walls. Promvonge et al [20] showed that if the test duct is sufficiently large, then the duct flow can be considered as the fully developed periodic flow. In the present study periodic domain was used. A constant mass flow rate of air with $300 \mathrm{~K}$ as the inlet temperature was considered in the flow direction. The air flowed over the inline $90^{\circ}$ and $60^{\circ} \mathrm{V}$-shaped broken ribs. The flow was considered to be periodic, three-dimensional, fully developed, turbulent and incompressible. The physical properties of the air were assumed to be constant at the initial temperature of air. We have neglected the effect of body forces, radiation heat transfer and viscous dissipation. The no slip boundary condition was used over the duct walls as well as on the rib surfaces apart from the enhanced wall treatment to model turbulence in the vicinity of a solid wall. A constant heat flux of $2500 \mathrm{~W} / \mathrm{m}^{2}$ was applied at the two opposite vertical heated walls of the square duct and ribs were considered adiabatic [1].

Figure 3 shows the computational domain considered for $60^{\circ} \mathrm{V}$-shaped broken ribs. The periodic boundary condition was used at the inlet and outlet of computational domain. Grid selection is one of the important parts of the numerical simulation and it is up to a user to design a grid, i.e., a suitable negotiation between the desired accuracy and solution cost. In the present study grids were made much finer at critical locations, such as near the walls, ribs, separation region and near the reattachment.

\section{Results and discussion}

With an aim to provide generalized results, normalized coordinates are used to present various results. The local Nusselt number $(\mathrm{Nu})$ and average Nusselt number $\left(N u_{a v}\right)$ 
were normalized by the Nusselt number $\left(N u_{0}\right)$ for smooth channel given by Dittus-Boelter correlation. The streamwise coordinate $(x)$ was normalized with the rib height $(e)$ and the spanwise coordinate $(z)$ was normalized by the channel hydraulic diameter $(d)$.

A grid independence study was carried out for the attached $60^{\circ} \mathrm{V}$-shaped broken ribs (figure 4). Four different grids with 264,268, 359,600, 420,968 and 492,492 number of cells were considered. A variation of the normalized local Nusselt number along with the normalized streamwise location at $z / d=1 / 4$ in the spanwise direction for $R e=15,000$ were compared. We observed that for three fine meshes the variation of the normalized local Nusselt number was negligible (figure 4) and therefore mesh with 359,600 cells was used for further study.

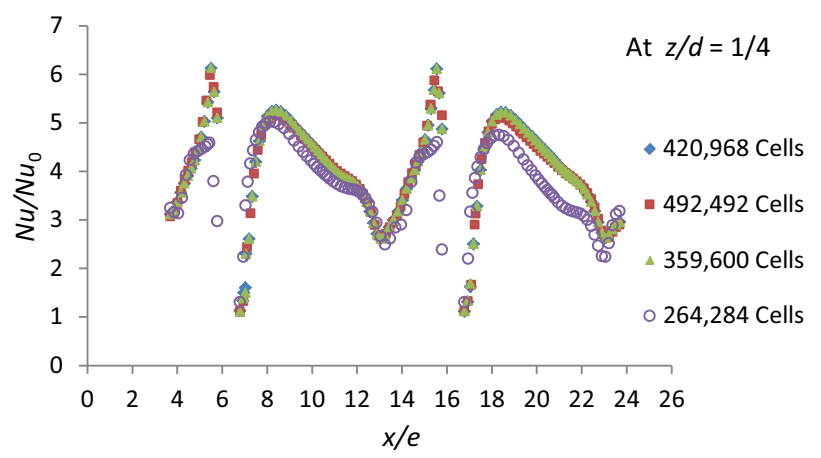

Figure 4. Variation of normalized local Nusselt number for different meshes for $60^{\circ} \mathrm{V}$-shaped broken attached ribs for $e /$ $d=0.0625, p / e=10$ and $R e=15,000$.

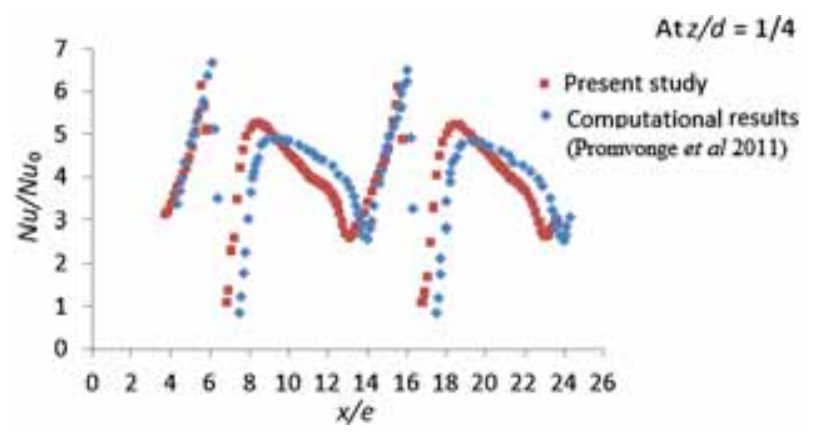

Figure 5. Variation of the local Nusselt number for $60^{\circ}$ $\mathrm{V}$-shaped broken ribs with available computational results for $e$ / $d=0.0625, p / e=10$ and $R e=15,000$.
The present code was validated with the computational results obtained by Promvonge et al [20] for a horizontal duct fitted with $60^{\circ} \mathrm{V}$-shaped broken attached ribs. Figure 5 shows a variation of the normalized local Nusselt number for $60^{\circ} \mathrm{V}$-shaped broken ribs in the stream-wise direction and at $z / d=1 / 4$ in the span-wise direction for $e / d=0.0625, s / d=0.0625$ and $p / e=10$ at a Reynolds number of 15,000 . The variation in the normalized local Nusselt number for the present study is in good agreement with the computational results obtained by Promvonge et al [20]. A small variation was observed in the average Nusselt number between the present results and those obtained computationally by Promvonge et al [20] with $10 \%$ and experimentally by Sriharsha et al [1] with $1.54 \%$ as shown in table 1.

In order to check the grid independence for the present study of $90^{\circ}$ attached ribs, four different meshes with element numbers of 152,952, 243,300, 342,500 and 427,272 were considered. From figure 6 it is clear that for the meshes with number of elements equal to 342,500 and 427,272 the variation of the normalized local Nusselt number is negligible. Thus solution using these two fine meshes can be considered as the grid independent.

In the present study, the performances of three turbulence models, namely, the standard $k-\varepsilon$ model, RNG $k-\varepsilon$ model and realizable $k-\varepsilon$ model, were compared for calculating the Nusselt number over the heated plate where the ribs are placed. We observe from figure 7 that there is a small difference in the local Nusselt number values

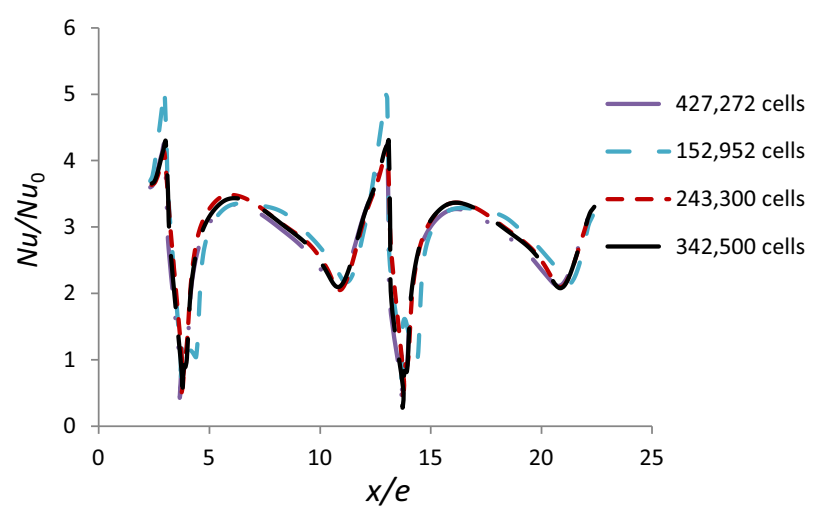

Figure 6. Variation of the normalized local Nusselt number for different number of cells for $90^{\circ}$ continuous attached rib for $e /$ $d=0.15, p / e=10$ and $R e=15,000$.

Table 1. Comparison of average Nusselt number.

\begin{tabular}{|c|c|c|c|c|c|}
\hline S. no. & Nature of study & $\operatorname{Re}$ & $p / e$ & $e / d$ & $N u_{a v} / N u_{0}$ \\
\hline 1. & Present results & 15,000 & 10 & 0.0625 & 3.96 \\
\hline 2. & Computational results [20] & 15,000 & 10 & 0.0625 & 3.60 \\
\hline 3. & Experimental results [1] & 15,000 & 10 & 0.0625 & 3.90 \\
\hline
\end{tabular}




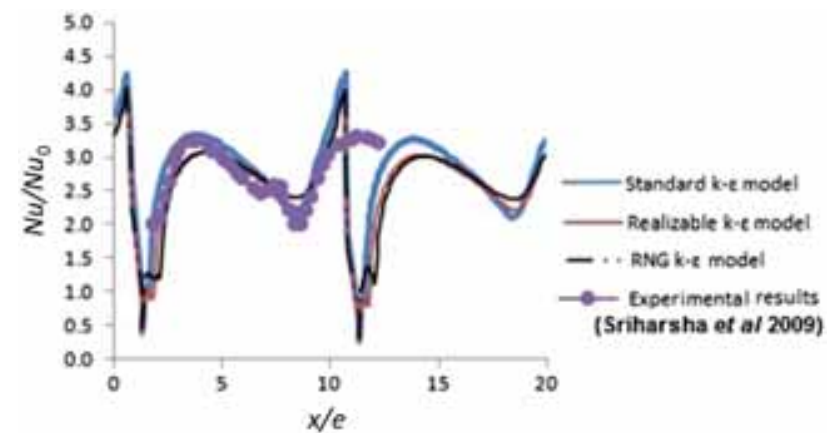

Figure 7. Predicted variations of the local Nusselt number compared with experimental data for $90^{\circ}$ continuous attached rib with $p / e=10, e / d=0.15$ and $R e=15,000$.

Table 2. Average Nusselt number predicted by different turbulence models for $e / d=0.15, p / e=10$ and $R e=15,000$.

\begin{tabular}{lcc}
\hline S. no. & Turbulence model & $N u_{a v} / N u_{0}$ \\
\hline 1. & Standard $k-\varepsilon$ model & 2.75 \\
2. & Realizable $k-\varepsilon$ model & 2.69 \\
3. & RNG $k-\varepsilon$ model & 2.71 \\
\hline
\end{tabular}

predicted by the standard $k-\varepsilon$ model, RNG $k-\varepsilon$ model and realizable $k-\varepsilon$ model. Overall, the present predictions by three turbulence models are in good agreement with the experimental data of Sriharsha et al [1].

Table 2 shows that there is a small variation in the average Nusselt number predicted by different turbulence models and these are in good agreement with the experimental results of Sriharsha et al [1] with a maximum deviation of $9.56 \%$. The variation in the local Nusselt number over the heated plate predicted by the standard $k-\varepsilon$ turbulence model is in good agreement with the experimental results obtained by Sriharsha et al [1] compared to that by other two models. Therefore, for the subsequent computations we have used the standard $k-\varepsilon$ model with the enhanced wall treatment.

Figure 8 shows the spanwise local Nusselt number distribution over the heated plate at three different locations in the spanwise direction. The results show that the normalized local Nusselt number is approximately same at all three locations for $90^{\circ}$ continuous attached ribs. This is because the ribs are continuous and recirculation and separation occur nearly at the same location and therefore the flow field is nearly the same at all locations. Thus variation in the local Nusselt number distribution in the spanwise direction is negligible.

It can be observed from figure 9 that the turbulent kinetic energy $(k)$ is marginally higher between the ribs and it suddenly decreases after the attached solid ribs. We can observe from figures 8 and 9 that the region of increased or decreased local Nusselt number is at the same location as

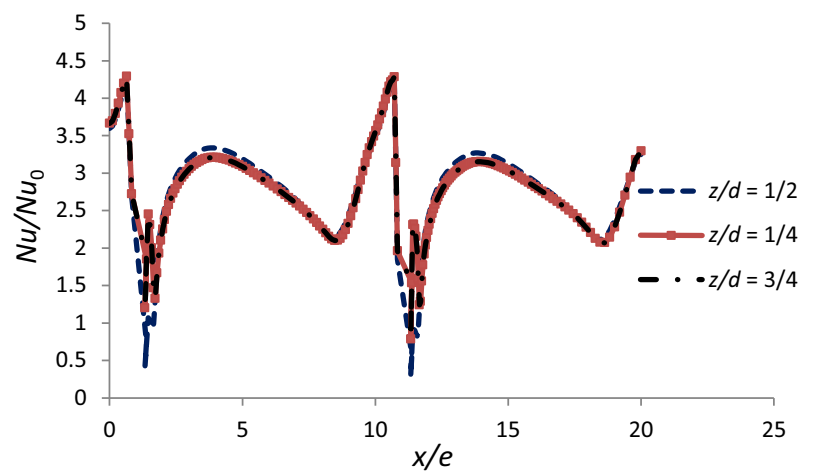

Figure 8. Spanwise local Nusselt number distribution for $90^{\circ}$ continuous attached ribs for $e / d=0.15, \quad p / e=10$ and $R e=15,000$.

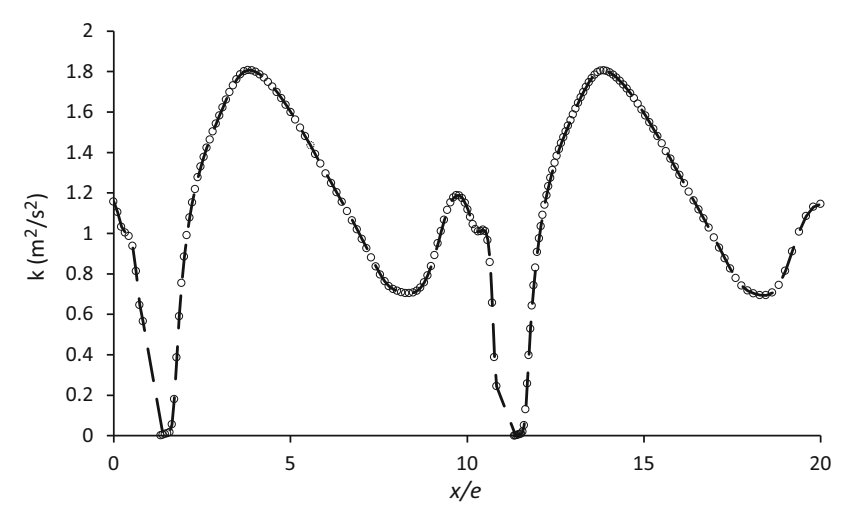

Figure 9. Spanwise turbulent kinetic energy distribution for $90^{\circ}$ continuous attached ribs for $e / d=0.15, \quad p / e=10$ and $R e=15,000$.

the corresponding region of $k$ because local heat transfer increases or decreases with corresponding increment or decrement of $k$. The existence of ribs in any closed channel decreases the flow area causing the acceleration of the flow near the ribs and acceleration and sudden expansion of the flow in the rib region produces the flow separation from the wall and further its reattachment at some downstream location. We can see the occurrence of flow separation and the reattachment of the flow in between the ribs (figure 15) and after the reattachment point, the boundary layer starts developing in the direction of flow. Because of an increase in the boundary layer thickness $k$ decreases and hence the heat transfer and the local maxima of $k$ can be observed at the reattachment point i.e. around $x / e=4$ for $p / e=10$. Reduction in $k$ and hence the local Nusselt number is due to the formation of large recirculation region immediately behind the attached solid rib (figures 14 and 15).

From figure 10 it is clear that the maximum heat transfer takes place at the normalized rib spacing $(p / e)=10$. The separation of flow occurs at the rib surface and is followed by the reattachment between the ribs (figure 15) as the rib height is same for all $90^{\circ}$ attached rib configurations, the 


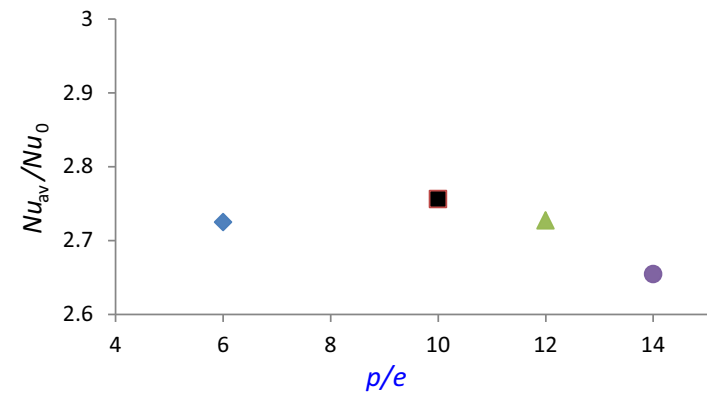

Figure 10. Area average Nusselt number ratio for different nondimensional rib spacing $(p / e)$ for $e / d=0.15$ and $R e=15,000$.

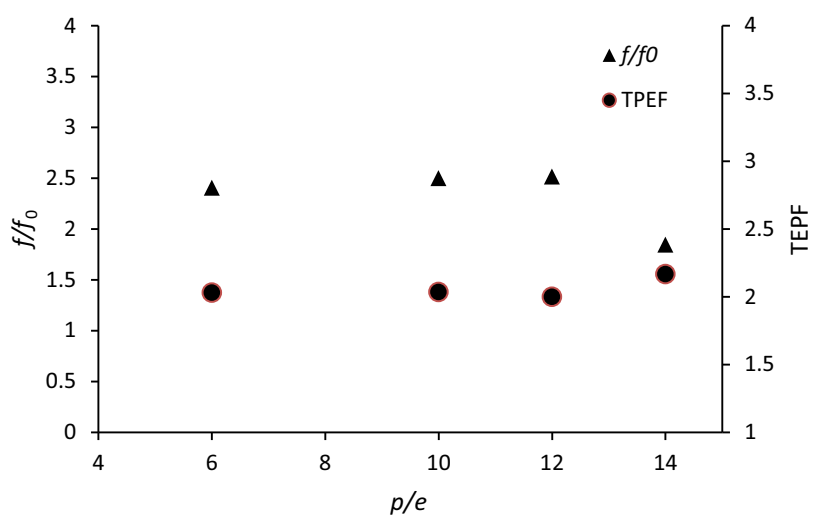

Figure 11. Variation of $f / f_{0}$ and TEPF at different $p / e$ for $90^{\circ}$ continuous attached ribs for $e / d=0.15$, and $R e=15,000$.

reattachment point is nearly the same. But as the rib spacing increases, thus the area after the reattachment point increases and the boundary-layer thickness increases in the direction of flow for $p / e=10,12$ and 14 . Because of an increase in the boundary-layer thickness, turbulent kinetic energy decreases and we observed that the maximum heat transfer occurs at $p / e=10$. Therefore we can say that as the rib spacing increases, turbulent kinetic energy decreases and consequently the heat transfer decreases. If the rib spacing decreases then the flow does not effectively reattach between the ribs. This behavior leads to a decrease in the turbulent kinetic energy and thus the heat transfer decreases. Figures 10 and 11 show that the highest heat transfer occurs with $p / e=10$ but at a cost of increased friction factor. A slightly better thermal performance was observed with $p / e=14$ compared to other spacings considered.

Figure 11 shows the variation of friction factor and thermal performance at different rib pitches $(p / e)$ for $90^{\circ}$ continuous attached ribs for constant $e / d=0.15$ and $R e=15,000$. It can be observed that for $p / e=6,10$ and 12 the variation in the friction factor $\left(f / f_{0}\right)$ is small, however, for $p / e=14$ the friction factor decreases sharply as compared to other pitch ratios considered. We have also observed that the variation in the rib spacing with constant blockage ratio has almost negligible effect on the thermal enhancement performance factor.

Figure 12 shows the surface Nusselt number contours for $90^{\circ}$ continuous attached ribs. It can be seen from figure 10 that heat transfer deteriorates immediately after the rib and achieves the maximum value before each rib. The deterioration of heat transfer behind the rib is due to a large recirculation zone formed immediately after the attached rib.

Figure 13 shows the effect of Reynolds number on friction factor and thermal performance for $90^{\circ}$ continuous attached ribs for $e / d=0.15$ and $p / e=10$. It can be observed from figure 13 that the friction factor increases with an increase in $R e$ and a small variation observed in thermal enhancement performance factor with the variation of Reynolds number. We can observe a minor increment in the thermal performance with $R e$ in the range of $15,000-30,000$ but at a cost of increased friction factor and hence pumping power. Figure 14 shows the contours of turbulent kinetic energy for $90^{\circ}$ continuous attached ribs. It can be observed that turbulent kinetic energy is the highest
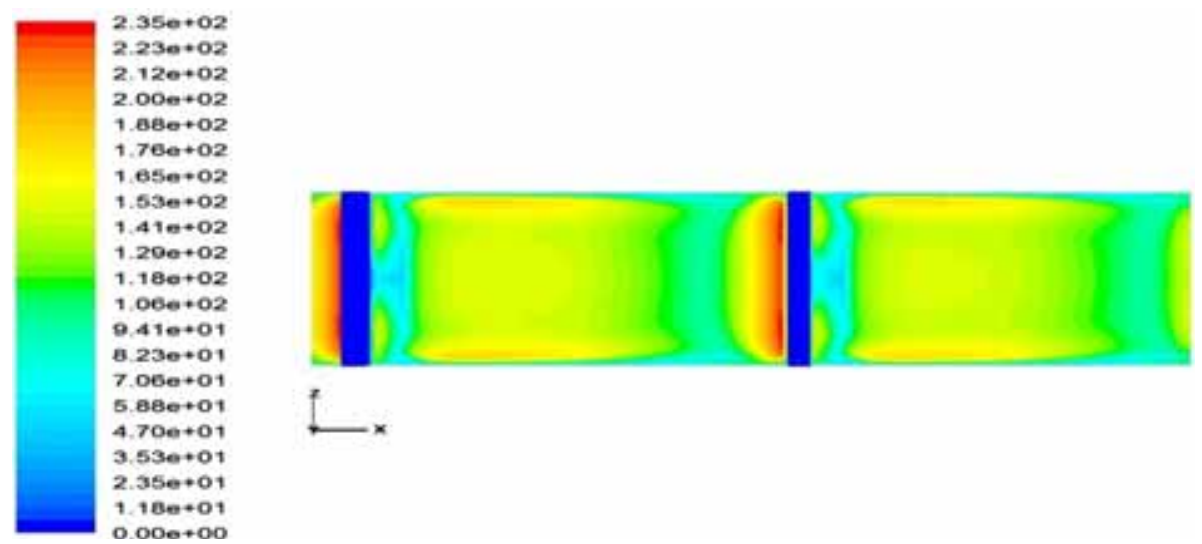

Figure 12. Surface Nusselt number contours on heated plate for $90^{\circ}$ continuous attached ribs for $e / d=0.15, p / e=10$ and $R e=15,000$. 


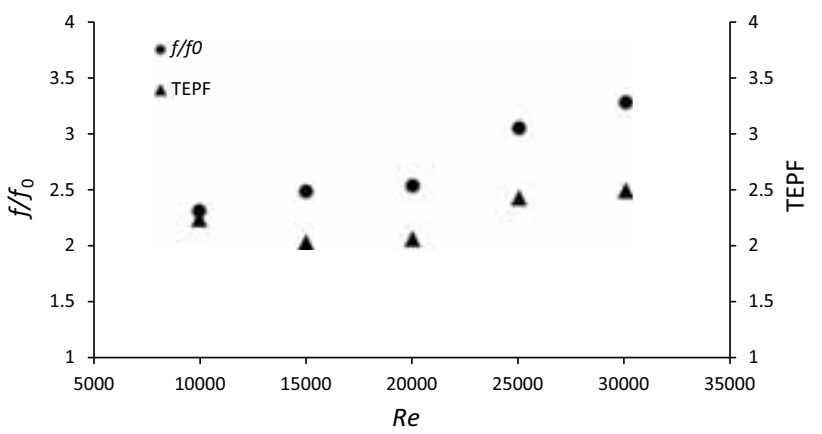

Figure 13. Variation of $f / f_{0}$ and TEPF at different $R e$ for $90^{\circ}$ continuous attached ribs for $e / d=0.15$ and $p / e=10$.

at the point of impingement and this is the reason for the heat transfer to be the maximum at this point. While the minimum value of turbulent kinetic energy can be observed immediately behind the rib, this is due to a recirculation zone formed behind the rib and due to this behavior heat transfer deterioration takes place immediately after the rib.

Figure 15 shows the contours of mean velocity for $90^{\circ}$ continuous attached ribs with $e / d=0.15$ and $p / e=10$.
The point of reattachment and the zone of recirculation and impingement can be clearly seen.

We can observe from table 3 that the average heat transfer is more in case of $60^{\circ} \mathrm{V}$-shaped broken attached ribs because it produces more complex and mixed flow field as compared to $90^{\circ}$ continuous attached ribs.

\subsection{Effect of blockage ratio and rib thickness for $60^{\circ} \mathrm{V}$-shaped broken ribs}

The blockage ratio $(e / d)$ and rib thickness $(s / d)$ have significant effect on flow field and hence on heat transfer characteristics for rib roughened duct flow. A variation of the normalized local Nusselt number was considered for $60^{\circ} \mathrm{V}$-broken square ribs for the blockage ratios $(e / d)$ of $0.0625,0.08125,0.10$ and $p / e=10$ in the stream-wise direction and at $z / d=1 / 4$ for Reynolds number of 15,000 (figure 17). It can be observed from figure 17 that an increase in the blockage ratio $(e / d)$ and keeping rib spacing constant $(p / e=10)$ leads to a reduction in the local heat transfer. This is because an increase in the blockage ratio $(e / d)$ in the case of square $\mathrm{V}$-shaped broken rib increases

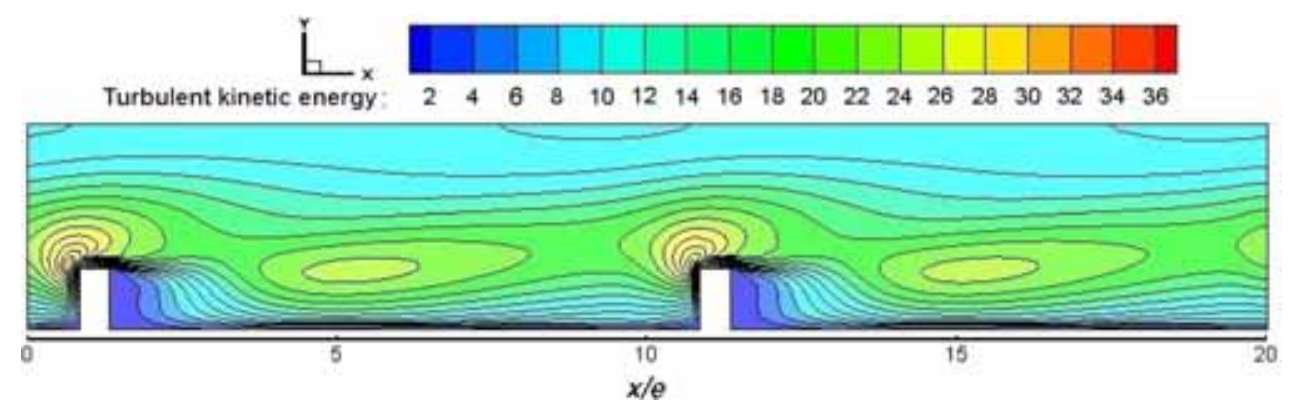

Figure 14. Contours of turbulent kinetic energy for $90^{\circ}$ continuous attached ribs with $e / d=0.15, p / e=10$ and $R e=15,000$.

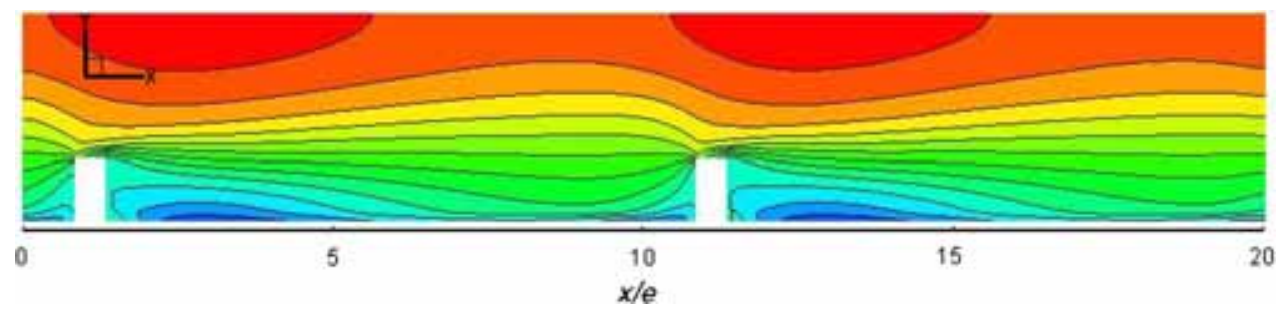

Figure 15. Contours of mean velocity for $90^{\circ}$ continuous attached ribs with $e / d=0.15$, p/e $=10$ and $R e=15,000$.

Table 3. Average Nusselt number for $90^{\circ}$ continuous and $60^{\circ} \mathrm{V}$-shaped broken attached ribs.

\begin{tabular}{lcccc}
\hline S. no. & Rib configurations & $p / e$ & $e / d$ & $N u_{a v} / N u_{0}$ \\
\hline 1. & $90^{\circ}$ continuous attached ribs & 10 & 0.15 & 2.75 \\
2. & $60^{\circ}$ V-shaped broken attached ribs & 10 & 0.15 & 3.15 \\
\hline
\end{tabular}


Table 4. Variation of $f / f_{0}$ and TEPF for different rib configurations at $p / e=10$ and $R e=15,000$.

\begin{tabular}{lccc}
\hline S. no. & Rib configuration & $f / f_{0}$ & TEPF \\
\hline 1 & $90^{\circ}$ attached $e / d=0.08125$ and $s / d=0.08125$ & 3.47 & 1.65 \\
2 & $60^{\circ} \mathrm{V}$-shaped broken attached $e / d=0.0625$ and $s / d=0.0625$ & 1.57 & 3.41 \\
3 & $60^{\circ} \mathrm{V}$-shaped broken attached $e / d=0.0625$ and $s / d=0.0125$ & 1.13 & 3.97 \\
4 & $60^{\circ} \mathrm{V}$-shaped broken attached $e / d=0.08125$ and $s / d=0.08125$ & 3.31 \\
5 & $60^{\circ} \mathrm{V}$-shaped broken attached $e / d=0.08125$ and $s / d=0.0125$ & 1.50 & 3.56 \\
6 & $60^{\circ} \mathrm{V}$-shaped broken attached $e / d=0.10$ and $s / d=0.10$ & 1.52 & 3.22 \\
7 & $60^{\circ} \mathrm{V}$-shaped broken attached $e / d=0.10$ and $s / d=0.0125$ & 3.41 \\
\hline
\end{tabular}

the rib height and this leads to a larger recirculation area behind the rib. The effect of increased blockage ratio in the case of broken ribs is found to have an unfavorable effect on the local heat transfer.

Table 4 shows the variation of friction factor and thermal enhancement performance factor for different rib configurations considered for $p / e=10$ and at $R e=15,000$. We have analyzed the thermal performance of $60^{\circ} \mathrm{V}$-shaped attached broken ribs and $90^{\circ}$ continuous attached ribs and the effect of blockage ratio and rib thickness for $60^{\circ}$ $\mathrm{V}$-shaped broken ribs on the friction factor and thermal enhancement performance factor. Here we can see that the thermal performance of $60^{\circ} \mathrm{V}$-shaped broken attached ribs is better than the $90^{\circ}$ continuous attached rib for the same configuration. We have observed that increasing the blockage ratio has an adverse effect on the thermal enhancement performance factor and thin ribs $(s / d=0.0125)$ performed better as comapred to the corresponding thick rib (for $60^{\circ} \mathrm{V}$-shaped broken ribs). We can also observe that the friction factor increases with increasing blockage ratio.

Figure 16 shows the contours of the surface Nusselt number for $60^{\circ} \mathrm{V}$-shaped broken square ribs for $p / e=10$ and blockage ratio $(e / d)=0.0625$. Following the discrete ribs it can be observed that the Nusselt number is high in front of the middle region of discrete attached ribs and it decreases before the side broken attached ribs. It can also be seen that the Nusselt number sharply decreases after each rib due to flow separation and reattachments.

In the present study we investigated the effect of the blockage ratio and for each blockage ratio thick and thin rib configurations were studied. Figure 18 shows a variation of the normalized average Nusselt number for $60^{\circ} \mathrm{V}$-broken ribs for different blockage ratios with two rib configurations, i.e., thick ribs and thin ribs, at different values of Reynolds number $(R e=10,000-30,000)$. It can be observed that the average Nusselt number decreases with an increase in the Reynolds number for all the cases. It can also be observed that by increasing the blockage ratio $(e / d)$ and keeping the normalized rib spacing ( $p / e)$ constant did not help in heat transfer enhancement. Therefore it can be concluded that increasing the blockage ratio $(e / d)$ and therefore increasing the rib height has an adverse effect on

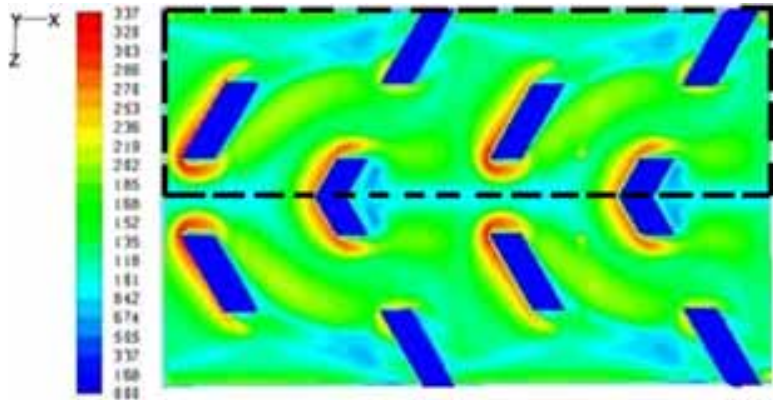

Figure 16. Surface Nusselt number contours for $60^{\circ} \mathrm{V}$-shaped broken attached ribs with $e / d=0.0625, \quad p / e=10$ and $R e=15,000$ (computed region is shown by dashed line).

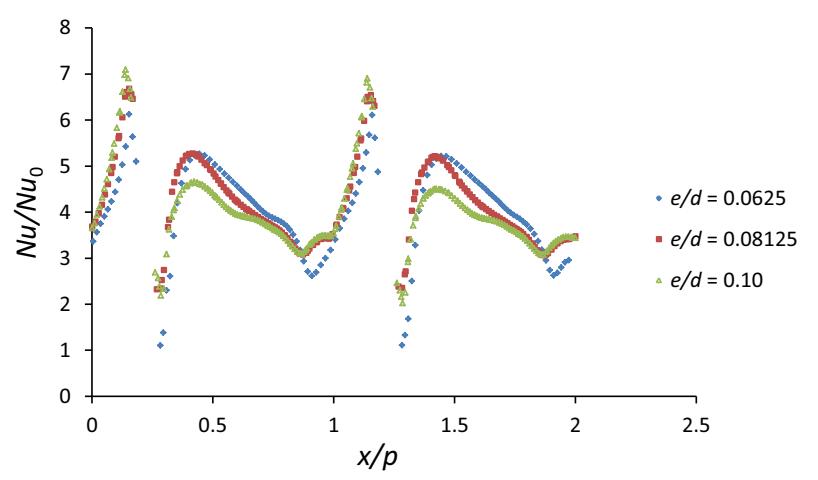

Figure 17. Effect of blockage ratio $(e / d)$ on variation of the local Nusselt number for $R e=15,000$ and at $z / d=1 / 4$.

the average heat transfer. We can observe from figure 18 that the average heat transfer slightly tends to increase with thin ribs as compared to that for square $60^{\circ} \mathrm{V}$-shaped broken thick ribs with a maximum increase of approximately $4-5 \%$.

\section{Conclusions}

A computational study was carried out in a three-dimensional square channel fitted with different types of ribs. The standard $k-\varepsilon$ model and its two variants (RNG and 


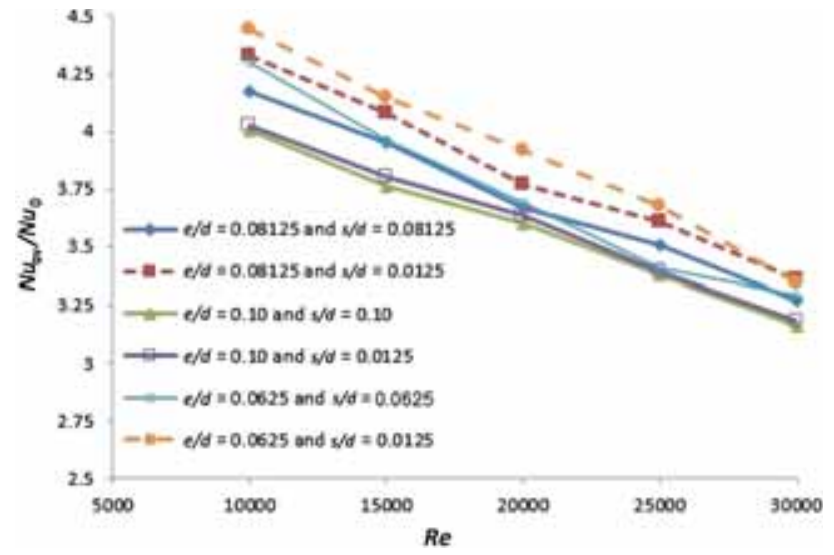

Figure 18. Variation of average Nusselt number for different blockage ratios and at different Reynolds numbers.

realizable) were used for turbulence modeling. The predictions were compared with available experimental results. The following conclusions may be drawn from the present study.

In the case of attached ribs a large recirculation zone is formed immediately after the ribs followed by reattachment between the successive ribs. Due to this behavior heat transfer deteriorates immediately after the rib. The maximum heat transfer occurs at the rib spacing $(p / e)=10$ but at a cost of increased friction factor for $90^{\circ}$ continuous attached rib configuration. Heat transfer enhancement as well as the thermal performance with the $60^{\circ} \mathrm{V}$-shaped broken ribs was observed to be the maximum compared to that for the $90^{\circ}$ continuous attached rib. We also observed that an increase in Reynolds number leads to a reduction in the average Nusselt number for almost all cases considered. For the $60^{\circ} \mathrm{V}$-shaped broken ribs, we observed that increasing the blockage ratio and keeping the rib spacing constant did not help in the heat transfer enhancement. Further, the average heat transfer slightly tends to increase with thin ribs $(s / d=0.0125)$ as compared to that for the square $60^{\circ} \mathrm{V}$-shaped broken ribs with a maximum increase of approximately $4-5 \%$. The present results can be used in designing cooling passages involved in various industrial heat enhancement devices.

\section{Appendix}

\section{Notation}

$\begin{array}{ll}A & \text { area }\left(\mathrm{m}^{2}\right) \\ C & \text { model constant } \\ c_{p} & \text { specific heat at constant pressure } \\ d & \text { hydraulic diameter }(\mathrm{mm}) \\ e & \text { rib height }(\mathrm{mm}) \\ e / d & \text { blockage ratio } \\ h & \text { heat transfer coefficient }\left(\mathrm{W} / \mathrm{m}^{2} K\right) \\ k & \text { turbulent kinetic energy }\left(\mathrm{m}^{2} / \mathrm{s}^{2}\right)\end{array}$

$\begin{array}{ll}k_{a} & \text { thermal conductivity of air }(\mathrm{W} / \mathrm{m}-K) \\ N u & \text { local Nusselt number }(h d / k) \\ N u / N u_{0} & \text { normalized local Nusselt number } \\ N u_{0} & \begin{array}{l}\text { Nusselt number obtained by Dittus-Boelter } \\ \text { correlation }\end{array} \\ N u_{a v} & \text { area average Nusselt number } \\ N u_{a v} \checkmark & \text { normalized avg. Nusselt number } \\ N u_{0} & \\ p & \text { rib pitch (mm) } \\ P & \text { mean pressure (Pa) } \\ p / e & \text { normalized rib spacing } \\ P r & \text { Prandtl number } \\ \operatorname{Re} & \text { Reynolds Number } \\ s & \text { rib thickness (mm) } \\ s / d & \text { normalized rib thickness } \\ U & \text { mean velocity } \\ \Phi & \text { scalar quantity } \\ \varepsilon & \text { rate of dissipation of turbulent } \\ \mu & \text { dynamic viscosity (kg/s-m) } \\ \mu_{t} & \text { eddy viscosity }\end{array}$

Subscripts

$b \quad$ bulk

$\mathrm{i}, \mathrm{j}, \mathrm{k}$ tensor notation

$t \quad$ turbulent quantities

$w \quad$ wall

\section{References}

[1] Sriharsha V, Prabhu S V and Vedula R P 2009 Influence of rib height on local heat transfer distribution and pressure drop in a square channel with $90^{\circ}$ continuous and $60^{\circ}$ V-broken ribs. Appl. Therm. Eng. 29: 2444-2459

[2] Webb R L, Eckert E R G and Goldstein R J 1971 Heat transfer and friction in tubes with repeated-rib roughness. Int. J. Heat Mass Transfer 14: 601-617

[3] Han J C, Glicksman L R and Rohsenow W M 1978 An investigation of heat transfer and friction for rib roughened surfaces. Int. J. Heat Mass Transfer 21: 1143-1156

[4] Han J C, Zhang Y M and Lee C P 1991 Augmented heat transfer in square channels with parallel, crossed and V-shaped angled ribs. Trans. ASME 113: 590-596

[5] Han J C and Zhang Y M 1992 High performance heat transfer ducts with parallel broken and $\mathrm{V}$-shaped broken ribs. Int. J. Heat Mass Transfer 35: 513-523

[6] Braun H, Neumann H and Mitra N K 1999 Experimental and Numerical investigation of turbulent heat transfer in a channel with a periodically arranged rib roughness elements. Exp. Therm. Fluid Sci. 19: 67-76

[7] Bonhoff B, Parneix S, Leusch J et al 1999 Experimental and numerical study of developed flow and heat transfer in coolant channels with $45^{\circ}$ ribs. Int. J. Heat Fluid Flow 20: 311-319 
[8] Gao X and Sunden B 2001 Heat transfer and pressure drop measurements in rib roughened rectangular channel. Exp. Therm. Fluid Sci. 24: 25-34

[9] Chandra P R, Alexander C R and Han J C 2003 Heat transfer and friction behaviors in rectangular channels with varying number of ribbed walls. Int. J. Heat Mass Transfer 46: 481-495

[10] Kim H M and Kim K Y 2004 Design optimization of rib roughened channel to enhance turbulent heat transfer. Int. J. Heat Mass Transfer 47: 5159-5168

[11] Tanda G 2004 Heat transfer in rectangular channels with transverses and $\mathrm{V}$-shaped broken ribs. Int. J. Heat Mass Transfer 47: 229-243

[12] Gao X and Sunden B 2004 PIV measurements of the flow field in rectangular ducts with 60 degree parallel, crossed and V-shaped ribs. Exp. Therm. Fluid Sci. 28: 639-653

[13] Onbasioglu S U and Onbasioglu H 2004 On enhancement of heat transfer with ribs. Appl. Therm. Eng. 24: 43-57

[14] Sewall E A, Tafti D K, Graham A B et al 2006 Experimental validation of Large Eddy Simulation of flow and heat transfer in a stationary ribbed duct. Int. J. Heat Fluid Flow 27: $243-258$

[15] Vijiapurapu S and Cui J 2007 Simulation of turbulent flow in a ribbed pipe using Large Eddy Simulation. Numer. Heat Transfer A 51: 1137-1165

[16] Gupta A, Sriharsha V, Prabhu S V et al 2008 Local heat transfer distribution in a square channel with 90 degree continuous, $90^{\circ}$ saw tooth profiled and $60^{\circ}$ broken ribs. Exp. Therm. Fluid Sci. 32: 997-1000

[17] Eiamsa-ard S and Promvonge P 2008 Numerical study of heat transfer of turbulent channel flow over periodic grooves. Int. Comm. Heat Mass Transfer 35: 844-852
[18] Tanda G 2011 Effects of rib spacing on heat transfer and friction in a rectangular channel with 45 degree angled rib turbulators on one/two walls. Int. J. Heat Mass Transfer 54: $1081-1090$

[19] Peng W, Jiang P X, Wang Y P et al 2011 Experimental and numerical investigations of convection heat transfer in channels with different types of ribs. Appl. Therm. Eng. 31: 2702-2708

[20] Promvonge P, Changcharoen W, Kwankaomeng S et al 2011 Numerical heat transfer study of turbulent square duct flow though inline V-shaped discrete ribs. Int. Comm. Heat Mass Transfer 38: 1392-1399

[21] Smulsky Ya I, Terekhov V I and Yarygina N I 2012 Heat transfer in turbulent separated flow behind a rib on the surface of square channel at different orientation angles relative to flow direction. Int. J. Heat Mass Transfer 55: 726-733

[22] Tang X and Zhu D 2013 Flow structure and heat transfer in a narrow rectangular channel with different discrete rib arrays. Chem. Eng. Process. 69: 1-14

[23] Vijiapurapu S and Cui J 2010 Performance of turbulence models for flows through pipes. Appl. Math. Model. 34: 1458-1466

[24] Dewan A 2011 Tackling turbulent flows in engineering. Germany: Springer, p. 124

[25] Launder B E and Spalding D B 1972 In: Lectures in mathematical models of turbulence. London England: Academic Press

[26] Pathak M, Dewan A and Das A K 2006 Computational prediction of a slightly heated turbulent rectangular jet discharged into a narrow channel crossflow using two different turbulence model. Int. J. Heat Mass Transfer 49: 3914-3928 